\title{
Lime modification of clay soils for construction expediency
}

\section{D. F. Rogers, S. Glendinning and T. E. J. Roff}

N. C. Consoli and A. Thome, Federal University of Rio Grande do Sul, Brazil

In their paper the authors present results from a series of laboratory texts on four British clays. These results are valuable for examining existing techniques for defining the amount of lime needed for the modification of clay soils, as well as for suggesting a new interpretation based on the full $\mathrm{pH}$ against lime addition curve.

The discussers have also been active in this area, although to date our tests have concentrated on soft clays containing some amount of organic matter mixed with high-calcium-grade quicklime. A comparison of our experience with those reported by the authors reveals some important areas of agreement, but also some disagreement on how to deal with the organic matter contained in the soil, as well as its effects on the soil. We would like to argue on the basis of recent data from initial consumption of time (ICL) tests, Atterberg limit testing, grain size results and unconfined compression tests carried out at the Federal University of Rio Grande do Sul, Brazil, on a Brazilian soft clay ${ }^{14,15}$ containing organic matter.

The results from material characterisation indicated that the major clay mineral is kaolinite, the organic matter content is high at about 3\%, leading to a $\mathrm{pH} 3.9$ and to a cation exchange capacity (CEC) of $26 \mathrm{meq} / 100 \mathrm{~g}$. It is important to point out that the CEC of the clay cleaned of organic matter is $3 \mathrm{meq} / 100 \mathrm{~g}$ and that the increase of CEC to $26 \mathrm{meq} / 100 \mathrm{~g}$ is due to the organic matter contained in the soil.

The results of ICL tests on the Brazilian soft clay are shown in Fig. 10 and the effect of lime addition after $24 \mathrm{~h}$ on the plasticity properties of the soil are presented in Fig. 11. Analysing Fig. 10, using the modified asymptotic ICL interpretation suggested by the authors, it has been found that $11 \%$ was the amount of lime needed for full modification. The Brazilian soft clay exhibited changes in plasticity due to lime addition (Fig. 11), requiring 11\% lime to effect full plastic limit (PL) changes. Consoli et al., ${ }^{15}$ analysing unconfined compression test results in the Brazilian clay-lime mixtures, observed that the minimum amount of lime required to cause long-term strength changes was $11 \%$. Thus, it can be concluded that both methods used to assess the minimum quantity of lime required to cause long-term strength changes based on the modified asymptotic ICL interpretation and lime to effect full PL changes predict the correct lime content.

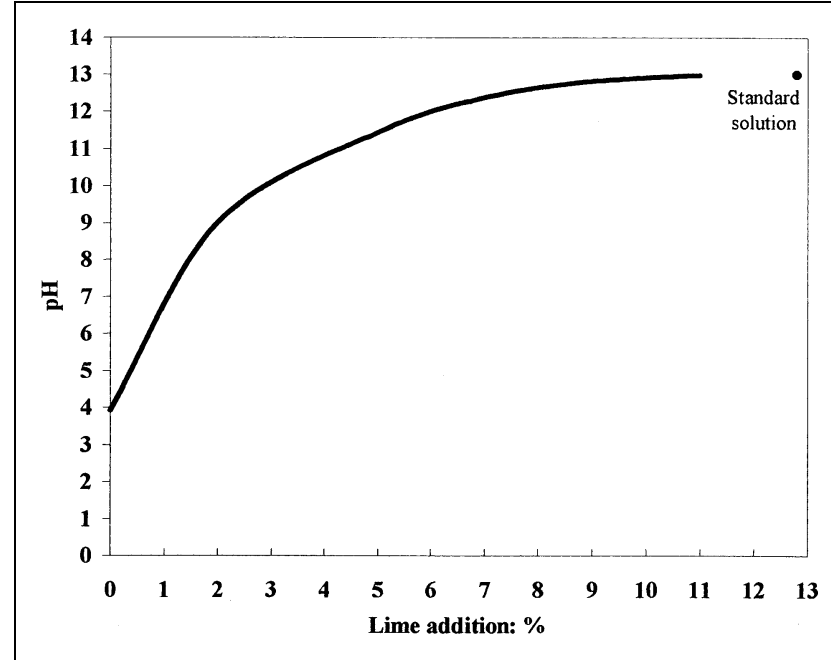

Fig. 10. ICL test results for Brazilian clay

The amount of lime required for full modification of the Brazilian clay $(11 \%)$ was considerably higher than that observed for the four British clays analysed by the authors (maximum 3\%). This difference is mainly due to the organic matter contained in the Brazilian clay. Thus, in the discussers' opinion, if organic matter is present in the soil, the samples cannot be cleaned of it, otherwise the results may be substantially affected.

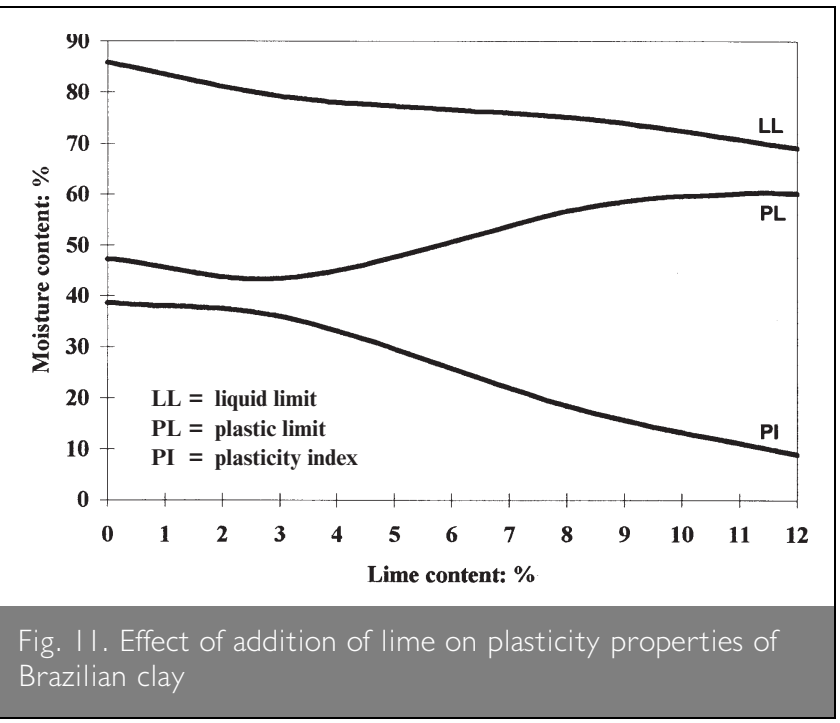




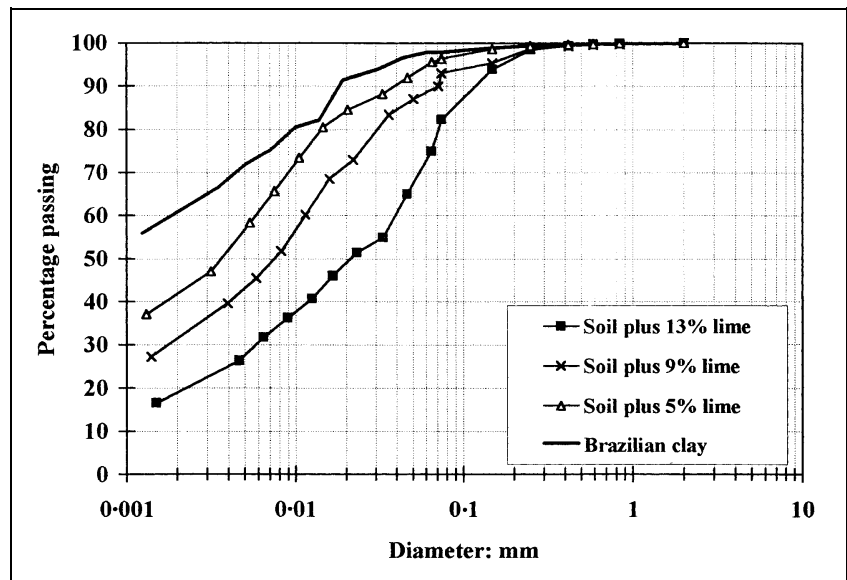

Fig. 12. Grain size distribution of Brazilian clay and mixtures of clay with $5 \%, 9 \%$ and $13 \%$ addition of lime

Finally, referring to the grain size distribution of the Brazilian clay-lime mixtures presented in Fig. 12, it can be seen that lime contents smaller than those needed for full modification are likely to be adequate in many cases, once the grain size modification due to flocculation has already occurred for lime additions below 11\%.

\section{Author's reply}

The authors wish to thank Consoli and Thorne for their contribution. It is interesting to see the results of UK research being applied overseas.

The results from their study appear to agree entirely with ours, suggesting that the existing ICL test would have significantly underestimated the quantity of lime required to achieve stabilisation (11\% as opposed to $7 \%$ ).

We would like to support the view that the quantity of lime calculated from the modified ICL test is, by definition, the quantity of lime required for full stabilisation. This, however, may not be the design requirement for the addition of lime. If modification (not stabilisation) is the desired effect then lower additions than the modified ICL value are likely to produce the desired outcome. Testing should, in that case, be based upon plasticity changes.

The discussion raises one further point of interest. The presence of organic matter is known to interfere with lime stabilisation by providing alternative 'preferential exchange sites' for the calcium ions. This has led to an upper limit of $2 \%$ organic matter permitted for lime stabilisation in current specifications. This has been based on low long-term strengths achieved by lime stabilised organic soils. If this was based on lime additions derived from the current ICL test, this could explain the poor results. The higher quantities of lime likely to be calculated by the modified ICL test may be sufficient to achieve the desired strength changes. This is worth further investigation.

\section{REFERENCES}

14. Thome A. Analysis of the Behaviour of a Soft Clay Treated with Lime. MSc dissertation (in Portuguese), Federal University of Rio Grande do Sul, Brazil, 1994.

15. Consoli N. C., Thome A. and Ceratti J. A. P. Engineering properties of organic soft soil-lime mixtures, Proceedings of the International Symposium on Recent Developments in Soil and Pavement Mechanics, Rio de Janeiro-Brazil, June 1997. Balkema, Rotterdam, 1997, pp. 217-222. 